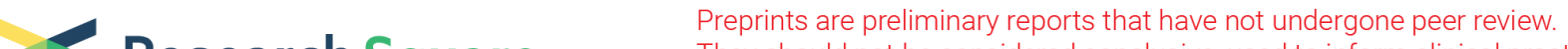 $\begin{array}{ll}\text { Research Square } & \text { They should not be considered conclusive, used to inform clinical practice, } \\ \text { or referenced by the media as validated information. }\end{array}$
}

\section{A facilitated social innovation: Stakeholder groups using Plan-Do-Study-Act cycles for perinatal health across levels of the health system in Cao Bang province, Vietnam}

\section{Anna Bergström ( $\square$ anna.bergstrom@kbh.uu.se )}

Uppsala Universitet Medicinska och farmaceutiska vetenskapsomradet https://orcid.org/0000-00034084-2336

\section{Dinh Phuong Hoa}

Vietnam National Hospital of Pediatrics: Benh vien Nhi Trung uong

Nguyen Thu Nga

Vietnam National Hospital of Pediatrics: Benh vien Nhi Trung uong

\section{Trieu Hoa}

Vietnam National Children's Hospital: Benh vien Nhi Trung uong

Tran Thanh Tu

Vietnam National Children's Hospital: Benh vien Nhi Trung uong

Pham Thi Lan Lien

Vietnam National Children's Hospital: Benh vien Nhi Trung uong

\section{Tran Trang}

Vietnam National Children's Hospital: Benh vien Nhi Trung uong

\section{Lars Wallin}

Dalarna University: Hogskolan Dalarna

\section{Lars-Åke Persson}

London School of Hygiene \& Tropical Medicine

\section{Leif Eriksson}

Uppsala universitet Disciplinary Domain of Medicine and Pharmacy: Uppsala Universitet Medicinska och farmaceutiska vetenskapsomradet

\section{Research}

Keywords: i-PARIHS, implementation science, knowledge translation, social innovation, facilitation, PDSA cycles, Vietnam, perinatal health

Posted Date: February 15th, 2022 
DOI: https://doi.org/10.21203/rs.3.rs-1332278/v1

License: (c) (1) This work is licensed under a Creative Commons Attribution 4.0 International License. Read Full License 


\section{Abstract \\ Background}

Universal coverage of evidence-based interventions for perinatal health could prevent most deaths, particularly if entire communities were engaged in the implementation. Social innovations may provide creative solutions to healthcare challenges, but their implementation relies on engaging communities and health system actors. This proof-of-concept study aimed to assess whether an earlier successful social innovation for improved neonatal survival that employed regular facilitated Plan-Do-Study-Act meetings on commune-level was feasible and acceptable when implemented on multiple levels of the health system (52 health units) and resulted in actions with plausibly favourable effects on perinatal health and survival in Cao Bang province, northern Vietnam.

\section{Methods}

The integrated Promoting Action on Research Implementation in Health Services (i-PARIHS) framework guided implementation and evaluation of the Perinatal Knowledge-Into-Practice (PeriKIP) project. Data collection included facilitators' diaries, health workers knowledge on perinatal care, structured observations of antenatal care, focus group discussions with facilitators, their mentors and representatives of different actors of the initiated stakeholder groups and an individual interview with the Reproductive Health Centre director. Clinical experts assessed the relevance of the identified problems and actions taken based on facilitators' diaries. Descriptive statistics included proportions, means, and ttests for the knowledge assessment and observations. Qualitative data were analysed by content analysis.

\section{Results}

The social innovation resulted in the identification of about 500 relevant problems. Also, $75 \%$ of planned actions to overcome prioritised problems were undertaken, results presented, and a plan for new actions to achieve the group's goals to enhance perinatal health. The facilitators had significant roles, ensuring that the stakeholder groups were established based on principles of mutual respect. Overall, the knowledge of perinatal health and performance of antenatal care improved over the intervention period.

\section{Conclusions}

The establishment of facilitated local stakeholder groups can remedy the need for tailored interventions and grassroots involvement in perinatal health and provide a scalable structure for focused efforts to reduce preventable deaths and promote health and well-being. 


\section{Contributions To The Literature}

- Social innovations could provide creative solutions to address healthcare delivery challenges for perinatal health.

- Implementation of regular facilitated meetings with stakeholders applying a structured process for undertaking tailored actions to locally identified problems ensured end-users involvement and development of a needs-based and responsive health system for perinatal health.

- Engaging communities and health system actors across different sectors of society in structured processes aiming to improve health and survival is a promising example of the enabling environments that the global 2030 agenda for women and children health and survival set out to achieve.

\section{Background}

The period with the most wide-ranging consequences for short- and long-term health and well-being is before and during delivery and the first four weeks after delivery, i.e., the perinatal period (1). Despite major progress during the last few decades, there are annually more than 1 million intrapartum-related stillbirths worldwide, 2.5 million deaths within the first month of life, and around 250,000 maternal deaths (2). Within global perinatal health, increased quality and coverage of a series of simple, evidencebased, and cost-effective practices can avert $70 \%$ of the neonatal deaths, $30 \%$ of the stillbirths caused during delivery (intrapartum), and $50 \%$ of maternal deaths $(3,4)$. The most crucial time for these evidence-based practices is during delivery and within the first week of life (5). With the Sustainable Development Goals launch, the global community has committed to ending preventable deaths of newborns and children under five years of age and ambitiously reducing maternal deaths by 2030 (6). With its direct and indirect effects on health, provision of health services and economy, the current pandemic threatens the maternal and child health gains of the last decades (7). There is now momentum to identify approaches to systematically fulfil these ambitions and provide evidence on how governments can implement these at scale.

Social innovations are usually seen 'as a set of processes that amalgamate combinations of up to three related propositions': new forms of collaboration, restructuring of social or power relations, and positive societal impact (8). Social innovations in health generally include community participation, engaging multiple stakeholders, being needs-based, and contributing to transformation in health and wellbeing (9). Community engagement is an essential factor driving this culture shift. Despite a growing body of evidence on the potential impact of community engagement $(10,11)$, maternal and child health services are often implemented without the end-users involvement (12). The result is a lack of trust and underutilisation of the health services, inequity in care utilisation, and stagnating health indicators. When (re)building post-pandemic maternal and child health, these aspects need consideration (7).

In implementation science, facilitation is described as a social approach to increase the use of evidencebased methods (13). Facilitation implies having a facilitator who enables others to implement a practice 
change and emphasises supporting rather than prescribing (14). Facilitation is commonly coupled with other social innovations, e.g., the Plan-Do-Study-Act (PDSA) - a powerful bottom-up approach that includes identifying and prioritising a locally identified problem followed by strategic action and careful monitoring.

The Newborn Knowledge Into Practice (NeoKIP) project in the Quang Ninh province, Vietnam, resulted in reducing neonatal mortality by half $\left(\mathrm{OR}_{\mathrm{adj}} 0.51 ; 95 \% \mathrm{Cl} 0.30-0.89\right)(15)$. The social innovation tested implied that local stakeholder groups, composed of primary care staff, local politicians and representatives of the local Women's Union, worked with a perinatal problem-solving approach. Trained facilitators recruited from the Women's Union, a well-established nationwide organisation, supported the local stakeholder groups. In addition to reducing the neonatal mortality rate, this social innovation also increased attendance to antenatal care (15) and increased equity in neonatal survival (16). In contrast to previous women's group studies (17), the NeoKIP innovation focused on initiating groups consisting of local health care staff and local stakeholders, i.e., trained professionals and influential commune members. The rationale for establishing this type of group was the feasibility of scaling up the innovation nationally if having sustained effect. This social innovation was primarily built upon local ownership and empowerment of the local stakeholders at the lowest hierarchical administrative and health system level. As expected, the implementation of the innovation did not result in an immediate effect on neonatal mortality. Instead, a delay in the effect was anticipated $(15,18-20)$. In NeoKIP, each stakeholder group met with their facilitator monthly over three years $(2008-2011)$. In 2014, a follow-up survey was conducted in the Quang Ninh province, three years after completing the trial. A sustained low level of the neonatal mortality rate was detected in the intervention communes (21). Like in other community-based strategies, the NeoKIP innovation did not show a reduction in stillbirths or intrapartumrelated neonatal deaths, which requires improved quality of care at the hospital level (22). This fact motivated future participatory interventions to be implemented at both primary care level and secondary (hospital) level to improve the quality of perinatal care provided. This need has also been expressed in a review of participatory action trials (17). Furthermore, the WHO recommends such approaches for improved perinatal health (23).

\section{Guiding theoretical framework}

The current project builds upon the integrated-Promoting Action on Research Implementation in Health Services (i-PARIHS) framework, which posits the interplay between the innovation to be implemented, the recipients who will either use the innovation or are targeted by the innovation (sometimes also referred to as 'end-users') and the context in which the innovation is implemented (24). The i-PARIHS presents facilitation as the ingredient that activates the implementation through assessing and responding to the characteristics of the other three components (24) (Figure 1). The current project evaluates a social innovation where facilitation functions to support the implementation of systematic improvement (innovation) through local stakeholder groups (recipients) on primary, secondary and tertiary health care levels (context). 
[Figure 1, here]

\section{Facilitation}

A successful implementation constitutes the four elements in the i-PARIHS framework (24). A facilitator has an essential role in knowledge translation, i.e., to assist teams in apprehending what needs to be changed in their local setting and facilitate the process where the teams identify how it can be changed $(14,25)$. The facilitator thereby holds an important position to achieve successful implementation. Recent reviews of facilitation have unanimously concluded that it is a promising approach for translating evidence into practice $(14,17,26,27)$. One commonly used method often coupled with facilitation is the action-oriented PDSA cycle (28). The PDSA cycle prescribes a four-stage cyclic learning approach to adapt changes aimed at improvement (Figure 2).

\section{[Figure 2 here]}

The pragmatic principles of PDSA cycles promote the use of a small-scale, iterative approach to test interventions or actions, enabling rapid assessment and providing flexibility to adapt changes to ensure fit-for-purpose solutions $(29,30)$. The characteristics of the PDSA is likely influencing its ability to diffuse into health systems in high-, middle- and low-income settings (28). Based on current evidence, the WHO recommends implementing facilitated PDSA on health facility and community levels for improving maternal and newborn health $(23,31,32)$. The PDSA approach can easily be integrated into systems and become a sustainable continuous learning and action method.

This study aimed to assess whether an earlier successful social innovation for improved neonatal survival that employed a Plan-Do-Study-Act approach on commune level, was feasible and acceptable when implemented on multiple levels of the health system and resulted in actions with plausibly favourable effects on perinatal health and survival.

\section{Methods}

\section{Study setting}

The Perinatal Knowledge-Into-Practice (PeriKIP) project was undertaken in Cao Bang province, situated in the northern part of Vietnam bordering China. Cao Bang province has about 520,000 inhabitants (33). The province consists of one town municipality and 12 rural districts and has 12 district hospitals and one provincial hospital. The province includes impoverished areas with a high proportion (94\%) of inhabitants belonging to ethnic minority groups (34) that have higher neonatal mortality than the majority (35). At the time of initial project discussions in 2014, the official neonatal mortality rate (NMR) in Cao Bang province was 14 death per 1,000 live births. However, official data on neonatal mortality in Vietnam has earlier been underestimated (36). Based on discussions between the research team, the Reproductive Health Centre, and the Provincial Health Bureau in Cao Bang, three districts were 
purposively selected based on unfavourable characteristics regarding neonatal deaths, geographical location, and proportion of home-based deliveries.

The Vietnamese provincial health system has three levels: (I) the primary healthcare at commune health centres, (II) the secondary referral level at the district hospitals and (III) the tertiary care level at provincial hospitals. Emergency and comprehensive obstetric services and inpatient care are provided at district or provincial-level hospitals. Commune health centres provide primary healthcare services, such as normal birth assistance, basic obstetric care, and outpatient care (37). The PeriKIP interventions were implemented in 52 health units; at 48 commune health centres from November $1^{\text {st }}, 2015$ to October $31^{\text {st }}$, 2016 , and at three district hospitals and the provincial hospital from November $1^{\text {st }} 2015$ to April $30^{\text {th }}$ 2017. The rationale for running the intervention on the hospital level six months longer was the perceived need of understanding the functionality of the social innovation on this higher level of care.

\section{Description of the social innovation}

The basic feature of the PeriKIP social innovation was that trained facilitators supported local stakeholder groups at the commune level and at district and provincial hospital levels in their efforts to improve perinatal healthcare practices. Seven laywomen from the Women's Union were recruited as facilitators on the commune level. Facilitator positions were advertised openly, and recruitment was based on applicants' previous experience of community activities and communication skills. A retired director (physician) of the Reproductive Health Centre on the provincial level in Cao Bang was recruited and trained to take the role as facilitator in the participating four hospitals. The project was implemented within the existing healthcare system (37) to increase the local accountability and ownership of quality improvement amongst stakeholders responsible for health (see Box 1). The PeriKIP groups at the three different levels were expected to meet once a month for the project's duration.

During two weeks, the research group trained facilitators with theoretical sessions, group discussions, and role-play activities. Topics covered group dynamics and quality improvement methods (brainstorming and the PDSA cycle). To facilitate discussions about perinatal care, the facilitators were introduced to basic evidence-based neonatal care per recommendations in the Vietnamese National Guidelines in Reproductive Health Care (38). Also, facilitators were briefed on the current health situation in their respective district and the function of the healthcare system concerning reproductive health. Guides on facilitators' roles, attitudes, responsibilities, and how to handle challenging situations were based on the i-PARIHS framework (24) and modified materials from the NeoKIP project (39). At the end of the training, facilitators practised their skills in rural communes and district hospitals outside the study area followed by feedback discussions on performance. One person with reproductive health responsibilities from each district was recruited as a mentor of the facilitators working in the communes of that district. These persons attended the facilitator training and participated in separate sessions focusing on how to mentor facilitators. A guide describing the role of the mentors was also developed and used to support the mentors in their role. 


\section{Data collection}

This study employed a mixed-methods design (40). Data were collected on the process and outcomes of the social innovation.

\section{Process evaluation and outcomes}

A process evaluation employing qualitative and quantitative methods prospectively tracked the implementation to describe how the social innovation was initiated, carried out and how participants responded to the innovation. The process evaluation was performed according to the UK Medical Research Council guidelines: implementation, mechanism of impact and context (41). We developed a logic model, underpinning the assumptions on which the intervention was thought to function (see Additional File 1). For each of the three components, key questions needing an answer to understand the process were formulated, followed by identifying the target population, data sources, procedures, and tools (see Additional File 1). The implementation of the innovation: What was delivered and how it was delivered, including the procedures used to approach and attract facilitators, mentors, and group stakeholders(recruitment), the participation(reach), and the efforts of the facilitators (dose). Mechanism of impact: The participants' responses to and interactions with the innovation. In this component we explored why specific reactions to the social innovation resulted in particular outcomes. Further, we also explored the problems the groups addressed, the type and relevance of prioritised issues, actions taken, the interaction between group and facilitator, and methods used. Context: What contextual aspects that influenced the innovation, the implementation, and the mechanism of impact, leading to different outcomes. The outcomes of the social innovation included relevance of identified problems and completion of PDSA cycles, knowledge of perinatal care, perspectives of gaining knowledge, and performance of antenatal care. The following data collection modes and tools were used to monitoring data of the three process evaluation components and the outcomes of the social innovation:

\section{The facilitators' diaries}

The facilitators' diaries contained information about the stakeholder groups' adherence to the PDSA approach (i.e., completed full cycles or not) and information about stakeholders' attendance, problems identified, why problems were prioritised, actions planned to address these problems, and whether actions were implemented as planned. The facilitators made notes in the diaries after each stakeholder group meeting.

\section{Knowledge assessment}


A questionnaire with 22 questions (see Additional file 2) for assessing staff knowledge on definitions on the perinatal and neonatal period $(n=2)$, antenatal care $(n=7)$, and postpartum care $(n=13)$ was developed based on the National Guidelines in Reproductive Health Care (38) and administered to health workers involved in the provision of care to pregnant and birthing women, newly delivered women and their newborns at the onset of the study and the end of the 12-month intervention.

\section{Provision of antenatal care at the commune level}

An observational checklist (see Additional file 3) for routine antenatal care visits was developed. It captured eight recommendations in the National Guidelines in Reproductive Health Care (38) and included 81 items (see Box 2). Assessments were made using a scale with the options Yes/No/Don't know/Cannot observe. Midwiferyteachers were trained to undertake structured and non-participatory observations of four women's antenatal care visits in each commune health centre at the beginning and the end of the PeriKIP project.

\section{[Box 2 here]}

\section{Qualitative data collection}

Facilitators participated in focus group discussions (FGDs) after the training, six months later, and after completing the project. A total of 15 FDGs with homogeneous groups of PeriKIP stakeholders from the commune level were undertaken in each district after 12 months: village health workers $(n=3)$, vicechairpersons $(n=3)$, midwives $(n=3)$, commune health centre heads $(n=3)$ and women's union representatives $(n=3)$. The rationale for undertaking FGDs with homogeneous groups was to understand how different stakeholders perceived their roles in the groups, allowing for potentially critical comments about other stakeholders' involvement. One FGD was undertaken with each of the PeriKIP groups at the hospital level $(n=4)$, and one with the three mentors. Lastly, one individual interview was undertaken with the Reproductive Health Centre director in Cao Bang province after 12 months of implementation. The qualitative data collection aimed at understanding the mechanisms of change: the acceptability, usefulness, and operationalisation of the intervention at different levels $(42,43)$. The question guides were inspired by the i-PARIHS (44) and the UK Medical Research Council framework (41). The FGDs and the interview were audio-recorded and lasted 60-90 minutes.

\section{Data analysis}

Two pairs in the research team (one neonatologist and one paediatrician in the first pair, one paediatrician and one general physician in the other pair) analysed the relevance of the identified problems and actions taken based on facilitators' diaries from the 52 facilities. The independent scoring of each analyst was discussed to reach a consensus. A maximum score of 22 points could be obtained in the knowledge assessment (1 point for each correctly answered question). Baseline and endline results 
were compared across levels of the health systems (commune health centres and hospitals) and categories of health workers (physician, midwife, and nurse). Data from the antenatal care observations were compared before and after the 12 months of PeriKIP intervention. Data from knowledge assessment and observations were entered using EpiData (version 3.1) and analysed in SAS (version 9.4). Descriptive statistics included proportions, means with $95 \%$ confidence intervals, and t-tests with $p$-values.

The qualitative data were transcribed verbatim, translated into English, and analysed by content analysis with both inductive and deductive features (45). First, each interview of each type (midwives, village health workers, PeriKIP groups at hospitals, facilitators) was read several times to get a naïve understanding. This step informed the decision to approach the material as one data set. After that, open coding was undertaken. Codes were written in the margin of each interview describing aspects of the content. Codes were sorted into sub-categories, thereafter sub-categories were sorted under categories, and finally categories were placed under four main categories, i.e., the i-PARIHS dimensions (Innovation, Recipients, Facilitation and Context). One relevant category, Gaining knowledge and insights, as identified in the qualitative analysis, could not be sorted under the i-PARIHS dimensions. This category is presented together with the study outcomes.

\section{Results}

The findings are presented as Implementation (reach and dose), Mechanisms of impact and Context (quality of facilitation, of the social innovation and the context in which it was implemented) and Outcomes (relevance of the identified problems and completion of the PDSA cycle, understanding of perinatal health issues, antenatal care practice, and accountability of quality improvement processes).

\section{Implementation}

\section{Reach}

\section{Launching}

Launching meetings were organised to introduce PeriKIP and create buy-in at provincial and district levels. On provincial level, there were representation from the Provincial Health Bureau and the Provinciallevel Reproductive Health Centre as well as district-level leadership representation from the Population committee, the Women's Union and the hospital leadership from each of the included districts. At the launching of the PeriKIP on district level, there were representatives from the commune level, i.e., representation from the Population committees (Nguyên Bình 16/20; Hà Quảng 17/19; Phục Hòa 9/9), Women's union (Nguyên Bình 18/20; Hà Quảng 14/19; Phục Hòa 8/9) and the Commune health centres (Nguyên Bình 20/20; Hà Quảng 19/19; Phục Hòa 9/9), the district level including representation form the District hospitals, the District Health Bureau and the District-level Reproductive Health Centres as well as representation from the Provincial-level Reproductive Health Centres.

\section{Attendance to PeriKIP meetings}


In total, 12 meetings were held in each commune (total 576 meetings across all included communes) and 18 meetings at each hospital (total 72 meetings across all included hospitals). Overall, the mean attendance of different representatives at PeriKIP group meetings was 95\% (range 86\%-100\%) (Table 1).

\section{[Table 1 here]}

\section{Mechanisms of impact and context}

In total, the 48 communes identified and initiated actions to tackle 416 problems during 12 months, while the four included hospitals identified and initiated actions targeting 88 problems during 18 months. Below, we present the qualitative findings using i-PARIHS' dimensions as main categories (Table 2).

\section{[Table 2 here]}

\section{The innovation}

The initiation of PeriKIP meetings was positively influenced by careful anchoring of the social innovation at the Provincial Health Bureau and the Reproductive Health Centre at the provincial and district level. All communes and hospitals were informed about PeriKIP from within the system. At the beginning of the implementation phase, i.e., the first 2-3 months, the facilitators were tense and many stakeholders found the meetings' intention unclear. Some feared the social innovation to be a way for higher levels to exercise control. The facilitator and the mentor spent time developing a trustful relationship. The groups initially focused on relatively limited and achievable problems. By the end of the project, all stakeholders could explain the purpose of the innovation and clearly describe the different steps of the PDSA cycle. The cycle provided an opportunity for everyone to contribute to the discussion, a structured way to review current practices, and a method allowing participants to register improvements and their impact.

Overall, the social innovation was perceived as useful, and the Plan and Study steps provided a structure of the work. Previously, many activities had been initiated but neither perceived to be adapted to the local context nor appropriately evaluated. Groups were encouraged by improvements that happened because of the groups' actions. Although many stakeholders had attended a range of meetings at the commune health centre or hospital in the past, they perceived PeriKIP meetings to be different. The main reason was that the facilitator encouraged participation by all stakeholders, whereas previous meetings focused on passive reporting. Initially, the groups moved slowly and stakeholders were quiet, but later the teamwork improved and all stakeholders could share ideas and became friendly and confident to participate in the discussion.

Overall, the stakeholders perceived their inclusion as key to achieving the objective of PeriKIP. Some thought the activities could be improved with more stakeholders in the group, e.g., having representatives from all villages in the commune-level groups. Others suggested additional stakeholders, e.g., representatives from the youth union that could contact newly married couples, or from farmers union 
that could bring up issues of food security and nutrition but also be a communication channel to their members to ensure that perinatal health and survival to be on the agenda also in other sectors of society.

Stakeholders could clearly articulate the reason for their involvement and provide a rationale for the participation of others. It was clear that they acknowledged the different stakeholders of the group as experts in different areas. Local authorities' engagement was commonly mentioned as a prerequisite for success, including the authorisation given by the district health bureau.

PeriKIP stakeholders identified problems based on their understanding of the local situation and by using available statistics. Issues were prioritised based on the feasibility of finding a solution (time, skills, knowledge, funding, and other resources), the urgency or severity of the outcome, and commonality. If stakeholders disagreed, they voted. Some villages in the same commune had different problems, why groups opted to address those in parts of their commune. The stakeholders listed resources used for action, e.g., materials used when sensitising community members. They would also ask facilitators to help finding new knowledge or act as a bridge to the Reproductive Health Centre's resources.

The opinions varied whether the social innovation should be integrated into routine practice. The participants articulated a fundamental understanding of the PDSA process, including all its steps, recognised the benefits of engaging different stakeholders, and recognised an external facilitator's role as catalysts. The perception was that the facilitator had other skills than the PeriKIP group stakeholders, and the fact that a person came to the commune solely for this purpose gave weight to the meetings. However, several suggested that this activity could be integrated into other arrangements, e.g., the commune health centre's meetings with all village health workers. As such, the social innovation and the PDSA model were seen as a way of working that could be sustained, maybe in a slightly different format.

\section{Recipients}

The PeriKIP group environment was inclusive with an active engagement in discussions. This characterisation was brought forward as a critical trait of the groups. The monthly meetings were fora for dialogue, mutual learning and formulating common goals.

Both facilitators and stakeholders recognised that the social innovation depended on all contributing to the group's work and ensuring accountability of the activities. All stakeholders considered themselves and found other stakeholders to be essential for the group. The vice-chairperson stood out as a decisionmaker in the commune groups, and in the hospital, the hospital, the head had that role. The participation of these individuals was indispensable for the facilitators.

The understanding of perinatal health problems varied within the groups and over time. Some stakeholders recognised gaining new knowledge; others got upset when stakeholders were ignorant. Stakeholders identified high attendance, being on time, and sharing responsibilities as principles for a well-functioning group. Initially, time for regular monthly meetings was a challenge in the 
hospital groups and some stakeholders were frustrated when identified problems were judged not to be feasible to tackle.

\section{Facilitation}

Both the facilitator and mentor positions were advertised for, thereafter recruitment followed. The facilitators recruited in the PeriKIP project shared several factors motivating them to become facilitators, including a wish to contribute to improving the health of women and children, changing and developing the situation in their area, and increasing awareness and knowledge of perinatal health among community members. In addition, facilitators also mentioned motivational factors relating to their situation, such as increasing their understanding of quality improvement and having a monthly salary.

The two-week training of facilitators was considered sufficient. During the training, facilitators gained a relatively clear understanding of their role. Undertaking role-plays and field visits were challenging but essential parts of the training. Some of the facilitators wanted more practical training, including communication skills. The mentors received the same training as facilitators and, in addition, separate sessions about their specific tasks. The facilitator and mentor guides were perceived as useful, and the content was generally sufficient to fulfil their functions.

At the start of the project, the facilitators were tense, but they were more confident in their roles after a few meetings. They developed their role by updating themselves on the internet and interacting with other facilitators and mentors. The distance was a barrier to interaction with others, and they wished for more regular opportunities to share experiences.

The study participants appreciated the facilitators. Facilitators had a dynamic role, varying with context and stakeholders. Study participants mentioned that facilitators asked stakeholders about perinatal health experiences from their villages, using non-technical terms, respectfully acknowledged participants' contributions. They kept contact with community members, summarised meetings, took notes, kept track of members' duties, encouraged and enthusiastically guided the discussions.

The facilitators trained group participants in the PDSA method and provided support throughout the project. Study participants expressed that the facilitators supported the stakeholders in the quality improvement processes. This assistance involved problem solving and encouragement but without making decisions for the group. The facilitator was seen as a person who understood the situation and supported the learning process. For example, the facilitators used the experience from one commune when helping another. The national guidelines for reproductive health (38) were introduced to the PeriKIP groups and used as sources of information when preparing for monthly meetings and selecting problems and actions.

Non-attendance required facilitators to act swiftly, contacting the missing stakeholder, stressing the importance of their contributions, updating the content they had missed, and sometimes involving the 
vice-chairperson or hospital head to motivate them to attend. When counteracting non-attendance, the assignment of the PeriKIP initiative was emphasised by higher health system levels.

The facilitators played an essential role in the PeriKIP project. They needed to be active and dynamic. At the commune level, the facilitators functioned well despite their lack of clinical experiences, but it was regarded as a necessity to have a professional health background at the hospital level. It was suggested that retired health care staff could be used as facilitators.

The mentors attended meetings to support the facilitators and kept in contact via mobile phones. The mentor provided support with clinical knowledge, through interaction with PeriKIP stakeholders, and in the PDSA process. Some mentors were however unsure if they were helping the facilitators in their role as they did not have the experience of facilitating local groups.

\section{Context}

There was a shortage of resources, both in the clinical practice and the facilitation process. Medicines, equipment, and staff, e.g., obstetricians and paediatricians, were scarce. In the facilitation process, there was some lack of material for the facilitators. Further, there were insufficient resources for travelling, material to attract people to meetings, suitable venues and communication materials, such as photos, videos, and illustrations.

Many conflicting traditions and norms existed in the study area. For example, men generally made decisions for women and were in charge of the family's money. There were traditions related to pregnancy and childbirth with adverse health consequences for pregnant women and their newborns. In Cao Bang, many minority groups exist, and as with any group with long-standing and culturally anchored traditions, there was a reluctance to change. Another obstacle was hesitance among females belonging to ethnic minority groups to discuss reproductive health with male PeriKIP stakeholders. Some women in the PeriKIP groups considered travelling in remote areas dangerous, as there was a risk of being robbed.

There were geographic barriers to seeking care. The distance was also difficult for monthly meetings and implementing activities in remote areas. There were also language barriers to the communication with minority groups in Cao Bang.

\section{Outcomes}

\section{Relevance of problems and actions}

There were 416 prioritised problems at commune level, of which $96 \%$ were perceived as relevant, while at the hospital level, there were 88 prioritised problems, and all were perceived as relevant. Table 3 presents the most common problems.

\section{[Table 3 here]}


The hospital groups worked with more problems than the commune groups (Table 4). Most problems identified on both levels were addressed by full PDSA cycles.

\section{[Table 4 here]}

\section{Knowledge assessment and perspectives of gaining knowledge}

Out of the 190 health care workers that completed the knowledge assessment before and after the intervention, there were 92 doctors, 55 midwives and 43 nurses. The respondents were working at commune health centres $(n=131)$ and hospitals $(n=59)$. Overall, the health workers increased their mean knowledge score from 10.8 before the intervention to 11.6 after the intervention $(p<0.05)$ of a maximum score of 22. Nurses increased their mean score with $1.2(p<0.05)$ and doctors with $0.8(p<0.05)$, while midwives increased their mean score with $0.4(p=0.19)$. Health care workers at the commune health centres increased their mean score with $0.7(p<0.05)$ and health care staff at hospitals with $0.9(p<0.05)$.

Gaining knowledge and insight was a category from the qualitative analysis. Recipients highlighted an increased need of knowledge among health care workers in a large number of areas, including various clinical skills, communication and understanding of the situation in the communes. Participating in the social innovation provided opportunities to learn from each other. Also, participation in PeriKIP made health workers realise the importance of their work and that change was possible.

\section{Observations of antenatal care}

Four observations were conducted in each of the 48 communes before and after the social innovation. The mean score increased in seven out of eight domains with $0.3-4.3(p<0.05)$. Only the domain dealing with recording patient information did not change (Table 5).

\section{[Table 5 here]}

\section{Discussion}

We have described a social innovation where facilitation supported the implementation of systematic improvement cycles using PDSA through local stakeholder groups on primary, secondary and tertiary healthcare levels. It resulted in high attendance at locally-driven meetings, where 489 relevant problems were identified and $75 \%$ of these were addressed in full Plan-Do-Study-Act cycles to enhance perinatal health. The facilitators had significant roles in ensuring that groups with multiple stakeholders were established and functioned based on principles of mutual respect at all health system levels.

The PeriKIP social innovation was built on establishing a systematic identification of local problems, solutions, and actions, as well as reflections on whether actions taken were beneficial and integrated and sustained in the health system. The foundation of this social innovation was that local ownership and governance were fundamentally important for a resilient health system that uses available resources effectively. Establishing this ownership required a structured approach and co-creation with key health 
system stakeholders. Through well-attended launching meetings all involved levels were informed about plans, participated in forming the project and contributed to the organisation. In the establishment of the PeriKIP innovation, members of local systems occupied all key positions, i.e., researchers were not in focus. In the previous NeoKIP project we successfully established local stakeholder groups on the primary level and reduced neonatal mortality substantially over three years (15). However, even if NeoKIP was established with local ownership in mind (20) and had successful results even beyond the project period (21), integration into the health system with sustained activities did not happen (37). The deficient ownership and integration in NeoKIP may be related to that involved researchers, both national and foreign, occupied crucial positions throughout the intervention period (37).

We applied facilitation to introduce and support the PDSA cycles at multiple levels of the healthcare system and in society. The stakeholder groups were inclusive, established through cross-hierarchical coalitions, where individuals representing different groups worked together to systematically improve the quality and utilisation of the services. The composition of the groups was essential to the successful results. Individuals with different areas of expertise were considered important pieces of the puzzle. However, including more stakeholders with influential positions in society could be an improvement. This social innovation was built on the NeoKIP experiences (15), and differed from the successful women's group interventions (17), even if facilitation was used in all these efforts. The intention with PeriKIP was not to create new groups but to recognise and work within the current health system organisation and existing meeting structure with stakeholders at multiple levels, who already had health, welfare, and health services as their responsibility. Therefore, in comparison with other initiatives $(15,17)$, we believe PeriKIP processes and results have better opportunities to be sustained.

The PDSA cycles resemble an audit-feedback process, whereby practice and performance are measured and compared to standards or targets. The audit-feedback processes may lead to small but potentially significant improvements (46). However, the outcomes depend on how feedback is given (46). The application of trained facilitators in the initiation of these kinds of strategies is critical to ensuring an open climate with carefully moderated and constructive discussions. The traditional audit-feedback processes commonly start with an adverse outcome of a patient based on a death review or similar. In contrast, the PDSA cycle fundamentally builds on the group's joint ownership of the problem. Targets and measures are developed from within, and improvement is commonly not a result of fault-finding on the individual level. It is not running the risk of becoming a blame game. The PDSA builds upon co-creation and departs from the recognition and involvement of stakeholders in the change process. The results show that the acceptability of this social innovation was good. Also, the facilitators' adaptation to their new role was fast, which was not the case in the NeoKIP project (47). This difference could be related to better training of facilitators and local ownership among stakeholders on all levels.

This study was not designed for evaluating health outcomes. The focus was on studying the process of the social innovation and if it resulted in concrete actions. An intervention period of 12-18 month is rather short, considering the type of innovation that was implemented. Still, improvements in outcomes were detected, both regarding staff knowledge and performance of the antenatal care. A large number of 
relevant problems were addressed and the majority of problems identified at hospital and commune health centres were managed in full PDSA cycles.

The adoption of the i-PARHIS framework to guide the intervention and the evaluation of the findings provided structure in this complex project. Although facilitation as a meta-strategy to achieve change is operationalised in the i-PARIHS framework, how to best design the training of facilitators remains unclear. There is a lack of guidance on how to ensure that facilitators are provided with adequate knowledge and skills to enact their role. Although we appreciate the inclusion of the component recipients in i-PARIHS, our impression of that label is that it indicates a passive position. Rather we see this component as target groups of innovations on different levels. In our case the target groups were also actors and co-creators, concepts which could potentially also be a more fitting description than recipients.

This social innovation was feasible to implement, acceptable among stakeholders across various healthcare levels in Vietnam, resulted in the identification of important problems and actions with plausibly favourable effects on perinatal health and survival, and could be scaled up in health systems of low- and middle-income countries. This approach could contribute to reaching the Sustainable Development Goal of ending preventable deaths of newborns and children under 5 years of age and reduce maternal mortality ratio by 2030 (6). In essence, the PeriKIP social innovation could serve as a model where implementation is understood, tailored and governed locally. The approach builds local capacity for implementation of old and new evidence-based methods and programs.

The PeriKIP social innovation was only running for 12 and 18 months, respectively, at different levels of the health system. That might be sufficient for the stakeholder groups to learn and running the PDSA. However, a longer time for continuing to monitor what happened thereafter would have been preferable. We were also not able to study the potential that the social innovation might have on increasing the opportunity for enhanced connectedness between levels of the health system. For the process to be institutionalised this innovation needs to be incorporated in the plans of the higher administrative structures of the health system.

\section{Conclusions}

Current global health goals will only be achieved through better health systems, which will rely on government and societal efforts. The 2030 agenda for women and children emphasises ending preventable deaths and promoting enabling environments for health and wellbeing. Despite a growing body of evidence on the impact of community engagement, maternal and child health services are often implemented without end-users involvement, resulting in a lack of trust, underutilization, inequity and stagnating health indicators. Lessons from the ongoing pandemic, in the global context of climate change, reinforce the need for bottom-up, grassroots involvement in maternal, newborn and child health.

\section{Abbreviations}


Focus Group Discussions (FGDs); integrated-Promoting Action on Research Implementation in Health Services (i-PARIHS; Neonatal Mortality Rate (NMR); Newborn Knowledge Into Practice (NeoKIP); Perinatal Knowledge-Into-Practice (PeriKIP); Plan-Do-Study-Act (PDSA)

\section{Declarations}

\section{Ethical approval and Consent to participate}

Ethical approval was obtained from the Vietnam National Children's Hospital (No 689, 2015-07-09). Participation in the study was voluntary. All participants were informed about the purpose of the study and verbal consent to participate was given before data collection. The pregnant women included in the structured observations gave informed consent for observers to be present in the room.

\section{Consent for publication}

All authors read and approved the submission of the final manuscript.

\section{Availability of data and materials}

In accordance with research ethics, the study participants were guaranteed anonymity.

Thus, in the information provided prior to the consent procedure, potential participants were assured that the data would be available and managed only by the researchers. Thus, the complete datasets, such as transcripts from interviews, are not publicly available in full. However, essential excerpts of the transcripts and other collected data can be made available from the corresponding author on reasonable request.

\section{Competing interests}

The authors declare that they have no competing interests.

\section{Funding}

Forte (grant no 2014-02733), the Department of Science and Technology under the Provincial People's Committee in Cao Bang, Uppsala University (grant no 2015/1148 for caring science research) and Uppsala University funds based on Agreement for Medical Education and Research funded this study. None of the funders has had any role in study design, data collection and analysis, decision to publish, or preparation of the manuscript. 


\section{Authors contribution}

The design of the PeriKIP social innovation was a collaborative effort by all authors. DPH and AB led the implementation of PeriKIP project including the development of tools. TT led the qualitative data collection and PTLL the quantitative. Rating of the relevance of identified problems and actions and level of completeness of the PDSA was undertaken by DPH, NN, TH and TTT whilst AB and LE led data analysis. $A B$ and $L E$ drafted the first version of the manuscript.

\section{Acknowledgments}

We are grateful to all who agreed to participate in interviews, respond to knowledge surveys and for agreeing to be observed. Further, the PeriKIP project would never have been possible without the collaboration initiated with the Provincial Health Bureau in Cao Bang and the Department of Maternal and Child Health at the Ministry of Health. The authors also wish to thank DR Sarika Chaturvedi for sharing her experiences of using vignettes.

\section{Authors' information}

\section{Affiliations}

Uppsala Global Health Research on Implementation and Sustainability, Department of Women's and Children's health, Uppsala University, Sweden

Anna Bergström, Leif Eriksson

Institute for Global Health, University College London, London, United Kingdom

Anna Bergström

Research Institute for Child Health, Vietnam National Children's Hospital, Hanoi, Vietnam

Dinh Phuong Hoa, Nguyen Thu Nga, Tran Thanh Tu, Pham Thi Lan Lien, Tran Trang

Hanoi University of Public Health, Hanoi, Vietnam

Dinh Phuong Hoa

Provincial ReproductiveHealth Bureau, Provincial Health Bureau, Cao Bang, Vietnam

Trieu Hoa

School of Education, Health, and Social Studies, Dalarna University, Falun, Sweden Lars Wallin 
London School of Hygiene \& Tropical Medicine, London, United Kingdom

Lars-Åke Persson

Department of Public Health and Caring Science, Uppsala University, Sweden

Leif Eriksson

Corresponding author

Anna Bergström

\section{References}

1. Blencowe H, Vos T, Lee AC, Philips R, Lozano R, Alvarado MR, et al. Estimates of neonatal morbidities and disabilities at regional and global levels for 2010: introduction, methods overview, and relevant findings from the Global Burden of Disease study. Pediatr Res. 2013;74(Suppl 1):4-16.

2. Collaborators GBDD. Global age-sex-specific fertility, mortality, healthy life expectancy (HALE), and population estimates in 204 countries and territories, 1950-2019: a comprehensive demographic analysis for the Global Burden of Disease Study 2019. Lancet. 2020;396(10258):1160-203.

3. Bhutta ZA, Das JK, Bahl R, Lawn JE, Salam RA, Paul VK, et al. Can available interventions end preventable deaths in mothers, newborn babies, and stillbirths, and at what cost? Lancet. 2014.

4. Lawn JE, Blencowe H, Waiswa P, Amouzou A, Mathers C, Hogan D, et al. Stillbirths: rates, risk factors, and acceleration towards 2030. The Lancet. 2016.

5. Lawn JE, Blencowe H, Oza S, You D, Lee AC, Waiswa P, et al. Every Newborn: progress, priorities, and potential beyond survival. Lancet. 2014;384(9938):189-205.

6. Every Woman Every Child. THE. GLOBAL STRATEGY FOR WOMEN'S. CHILDREN'S AND ADOLESCENTS' HEALTH (2016-2030). Italy: United Nations; 2015.

7. The Lancet Global H. Progressing the investment case in maternal and child health. Lancet Glob Health. 2021;9(5):e558.

8. Ayob N, Teasdale S, Fagan K. How Social Innovation 'Came to Be': Tracing the Evolution of a Contested Concept. J Social Policy. 2016;45(4):635-53.

9. van Niekerk L, Manderson L, Balabanova D. The application of social innovation in healthcare: a scoping review. Infect Dis Poverty. 2021;10(1):26.

10. Persson LA, Rahman A, Pena R, Perez W, Musafili A, Hoa DP. Child survival revolutions revisited lessons learned from Bangladesh, Nicaragua, Rwanda and Vietnam. Acta Paediatr. 2017;106(6):871-7.

11. World Health Organization and International Initiative for Impact Evaluation. An evidence map of social, behavioural and community engagement interventions for reproductive, maternal, newborn and child health. Geneva; 2017. 
12. Black RE, Taylor CE, Arole S, Bang A, Bhutta ZA, Chowdhury AMR, et al. Comprehensive review of the evidence regarding the effectiveness of community-based primary health care in improving maternal, neonatal and child health: 8. summary and recommendations of the Expert Panel. J Glob Health. 2017;7(1):010908.

13. Berta W, Cranley L, Dearing JW, Dogherty EJ, Squires JE, Estabrooks CA. Why (we think) facilitation works: insights from organizational learning theory. Implement Sci. 2015;10:141.

14. Harvey G, Loftus-Hills A, Rycroft-Malone J, Titchen A, Kitson A, McCormack B, et al. Getting evidence into practice: the role and function of facilitation. J Adv Nurs. 2002;37(6):577-88.

15. Persson L, Nga N, Målqvist M, Hoa D, Eriksson L, Wallin L, et al. Effect of Facilitation of Local Maternal-and-Newborn Stakeholder Groups on Neonatal Mortality: Cluster-Randomized Controlled Trial. PLoS Med. 2013;10(5):e1001445.

16. Malqvist M, Hoa DP, Persson LA, Ekholm Selling K. Effect of Facilitation of Local Stakeholder Groups on Equity in Neonatal Survival; Results from the NeoKIP Trial in Northern Vietnam. PLoS ONE. 2015;10(12):e0145510.

17. Prost A, Colbourn T, Seward N, Azad K, Coomarasamy A, Copas A, et al. Women's groups practising participatory learning and action to improve maternal and newborn health in low-resource settings: a systematic review and meta-analysis. Lancet. 2013;381(9879):1736-46.

18. Osrin D, Prost A. Perinatal interventions and survival in resource-poor settings: which work, which don't, which have the jury out? Arch Dis Child. 2010;95(12):1039-46.

19. Jokhio AH, Winter HR, Cheng KK. An intervention involving traditional birth attendants and perinatal and maternal mortality in Pakistan. N Engl J Med. 2005;352(20):2091-9.

20. Wallin L, Malqvist M, Nga NT, Eriksson L, Persson LA, Hoa DP, et al. Implementing knowledge into practice for improved neonatal survival; a cluster-randomised, community-based trial in Quang Ninh province, Vietnam. BMC Health Serv Res. 2011;11:239.

21. Eriksson L, Nga NT, Hoa DTP, Duc DM, Bergstrom A, Wallin L, et al. Secular trend, seasonality and effects of a community-based intervention on neonatal mortality: follow-up of a cluster-randomised trial in Quang Ninh province, Vietnam. J Epidemiol Community Health. 2018;72(9):776-82.

22. Knippenberg R, Lawn JE, Darmstadt GL, Begkoyian G, Fogstad H, Walelign N, et al. Systematic scaling up of neonatal care in countries. Lancet. 2005;365(9464):1087-98.

23. World Health Organization. WHO recommendation on community mobilization through facilitated participatory learning and action cycles with women's groups for maternal and newborn health. Geneva: World Health Organization; 2014.

24. Harvey G, Kitson A. Implementing Evidence-Based Practice in Healthcare: A Facilitation Guide. Routledge; 2015.

25. Kitson A, Harvey G, McCormack B. Enabling the implementation of evidence based practice: a conceptual framework. Qual Health Care. 1998;7(3):149-58.

26. Dogherty EJ, Harrison MB, Graham ID. Facilitation as a role and process in achieving evidence-based practice in nursing: a focused review of concept and meaning. Worldviews Evid Based Nurs. 
2010;7(2):76-89.

27. Thompson GN, Estabrooks CA, Degner LF. Clarifying the concepts in knowledge transfer: a literature review. J Adv Nurs. 2006;53(6):691-701.

28. Taylor MJ, McNicholas C, Nicolay C, Darzi A, Bell D, Reed JE. Systematic review of the application of the plan-do-study-act method to improve quality in healthcare. BMJ Qual Saf. 2014;23(4):290-8.

29. Greenhalgh T, Robert G, Macfarlane F, Bate P, Kyriakidou O. Diffusion of innovations in service organizations: systematic review and recommendations. Milbank Q. 2004;82(4):581-629.

30. Damschroder LJ, Aron DC, Keith RE, Kirsh SR, Alexander JA, Lowery JC. Fostering implementation of health services research findings into practice: a consolidated framework for advancing implementation science. Implement Sci. 2009;4:50.

31. Tuncalp, Were WM, MacLennan C, Oladapo OT, Gulmezoglu AM, Bahl R, et al. Quality of care for pregnant women and newborns-the WHO vision. BJOG. 2015;122(8):1045-9.

32. Chan G, Storey JD, Das MK, Sacks E, Johri M, Kabakian-Khasholian T, et al. Global research priorities for social, behavioural and community engagement interventions for maternal, newborn and child health. Health Res Policy Syst. 2020;18(1):97.

33. GENERAL STATISTICS OFFICE of VIET NAM. Area, population and poulation density in 2013 by province 2013 [April 16 2015]. Available from: http://www.gso.gov.vn/default_en.aspx? tabid=467\&idmid=3\&ltemID=15751.

34. World Health Organization. Health And Ethinc Minorities. In: Viet Nam. Technical series No.1. Hanoi. Vietnam: WHO; 2003.

35. Malqvist M, Nga NT, Eriksson L, Wallin L, Hoa DP, Persson LA. Ethnic inequity in neonatal survival: a case-referent study in northern Vietnam. Acta Paediatr. 2011;100(3):340-6.

36. Malqvist M, Eriksson L, Nguyen TN, Fagerland LI, Dinh PH, Wallin L, et al. Unreported births and deaths, a severe obstacle for improved neonatal survival in low-income countries; a population based study. BMC Int Health Hum Rights. 2008;8:4.

37. Eriksson L, Bergstrom A, Hoa DTP, Nga NT, Eldh AC. Sustainability of knowledge implementation in a low- and middle- income context: Experiences from a facilitation project in Vietnam targeting maternal and neonatal health. PLoS ONE. 2017;12(8):e0182626.

38. Ministry of Health Vietnam. National standards and guidelines for reproductive health care services. In: MoH, editor. Hanoi2009.

39. Eriksson L, Huy TQ, Duc DM, Ekholm Selling K, Hoa DP, Thuy NT, et al. Process evaluation of a knowledge translation intervention using facilitation of local stakeholder groups to improve neonatal survival in the Quang Ninh province. Vietnam Trials. 2016;17(1):23.

40. Creswell JW, Plano Clark VL. Designing and conducting mixed methods research. 2nd ed. Los Angeles, Calif.; London: SAGE; 2011. xxvi, 457 p. p.

41. Moore GF, Audrey S, Barker M, Bond L, Bonell C, Hardeman W, et al. Process evaluation of complex interventions: Medical Research Council guidance. BMJ. 2015;350:h1258. 
42. Lewin $S$, Glenton $C$, Oxman AD. Use of qualitative methods alongside randomised controlled trials of complex healthcare interventions: methodological study. BMJ. 2009;339:b3496.

43. Linnan L, Steckler A. Process evaluation for Public Health Interventions and Research. San Fransisco: Jossey-Bass; 2002.

44. Harvey G, Kitson A. PARIHS revisited: from heuristic to integrated framework for the successful implementation of knowledge into practice. Implement Sci. 2016;11:33.

45. Elo S, Kyngas $H$. The qualitative content analysis process. J Adv Nurs. 2008;62(1):107-15.

46. Ivers N, Jamtvedt G, Flottorp S, Young JM, Odgaard-Jensen J, French SD, et al. Audit and feedback: effects on professional practice and healthcare outcomes. Cochrane Database Syst Rev. 2012;6:CD000259.

47. Eriksson L, Duc DM, Eldh AC, Vu PN, Tran QH, Malqvist M, et al. Lessons learned from stakeholders in a facilitation intervention targeting neonatal health in Quang Ninh province, Vietnam. BMC Pregnancy Childbirth. 2013;13:234.

\section{Tables}

Table 1 Attendance to monthly PeriKIP meetings 
Attendance to monthly meetings per stakeholder category

\begin{tabular}{|c|c|c|}
\hline \multirow{8}{*}{$\begin{array}{l}\text { Commune level } \\
\text { PeriKIP groups } \\
(n=48)\end{array}$} & Head, commune health centres & $96 \%$ \\
\hline & Midwives & $96 \%$ \\
\hline & Vice chairperson & $91 \%$ \\
\hline & Village health worker representatives & $98 \%$ \\
\hline & Nurses & $97 \%$ \\
\hline & Population officers & $94 \%$ \\
\hline & Women's union representatives (community level) & $93 \%$ \\
\hline & Women's union representatives (village level) & $95 \%$ \\
\hline \multirow{8}{*}{$\begin{array}{l}\text { Hospital level } \\
\text { PeriKIP groups } \\
(n=4)\end{array}$} & Midwives working in antenatal care & $99 \%$ \\
\hline & Midwives working in labour ward & $99 \%$ \\
\hline & Head nurses of the paediatric departments & $94 \%$ \\
\hline & Head doctors of the obstetric departments & $94 \%$ \\
\hline & Head doctors of the paediatric departments & $99 \%$ \\
\hline & Heads of general planning departments & $96 \%$ \\
\hline & Representatives from the hospital director boards & $100 \%$ \\
\hline & $\begin{array}{l}\text { Representatives from the reproductive health centre at district or } \\
\text { provincial level }\end{array}$ & $86 \%$ \\
\hline
\end{tabular}

Table 2 Qualitative findings using i-PARIHS dimensions as main-categories organizing categories and sub-categories 


\begin{tabular}{|c|c|c|c|}
\hline Innovation & Recipients & Facilitation & Context \\
\hline $\begin{array}{l}\text { Initiation and } \\
\text { development of PeriKIP }\end{array}$ & $\begin{array}{l}\text { Recipients' engagement } \\
\text { in the social innovation }\end{array}$ & $\begin{array}{l}\text { Recruitment of facilitators } \\
\text { and mentors }\end{array}$ & Resources \\
\hline $\begin{array}{l}\text { Functionality and purpose } \\
\text { of the social innovation } \\
\text { - Apprehending the aim }\end{array}$ & Challenging situations & $\begin{array}{l}\text { Motivation to become a } \\
\text { facilitator }\end{array}$ & $\begin{array}{l}\text { Traditions } \\
\text { and norms }\end{array}$ \\
\hline With the project & & facilitator & Geograpny \\
\hline $\begin{array}{l}\text { - The composition of the } \\
\text { group }\end{array}$ & & $\begin{array}{l}\text { Training of facilitators } \\
\text { and mentors }\end{array}$ & \multirow{8}{*}{$\begin{array}{l}\text { Problems } \\
\text { reaching } \\
\text { groups }\end{array}$} \\
\hline - Role of the stakeholders & & - Development in the & \\
\hline $\begin{array}{l}\text { - Qualities of the social } \\
\text { innovation }\end{array}$ & & & \\
\hline Using the PDSA model & & $\begin{array}{l}\text { Being a facilitator } \\
\text { - Enabling successful } \\
\text { meetings }\end{array}$ & \\
\hline PDSA model & & - Strategies and tasks & \\
\hline - Identifying and & & - Handling challenges & \\
\hline • Using evidence & & $\begin{array}{l}\text { - Reflections on the } \\
\text { functionality of the } \\
\text { facilitation }\end{array}$ & \\
\hline $\begin{array}{l}\text { Sustainability of the } \\
\text { social innovation }\end{array}$ & & Supervision & \\
\hline
\end{tabular}

Table 3 Prioritised problems in PeriKIP groups

Table 4 Relevance of problems and actions 


\section{Top-prioritised problems at commune level (number of times prioritised across the $\mathbf{4 8}$ groups)}

- High rate of home delivery (34)

- Low awareness among pregnant women about self-care and newborn care (32)

- Pregnant women work hard during pregnancy (30)

- Women do not come for antenatal care according to national recommendation (29)

- Women avoid certain food after delivery (28)

- Poor nutrition among women during pregnancy (23)

- Smoking in the house where pregnant women and newly delivered mothers live (23)

- Poor preparedness for delivery (22)

- Difficult to detect pregnant women in first 3 months (22)

\section{Top-prioritised problems at} hospital level (number of times prioritised across the four groups)

- Lack of equipment (16)

- Lack of guidelines (7)

- Rooms for newborn care do not meet the hygiene standard (6)

- Midwives and nurses are not skilful in newborn resuscitation and essential newborn care (3)

- Poor counselling and support for immediate and exclusive breast feeding (3)

- Lack of training or Re-training on haemorrhage after delivery, mouth care, kangaroo mother care (3)

- Routine skin-to-skin contact after delivery is not practised (2)

- No screening for Hepatitis B for pregnant women (2)

- Poor knowledge and improper use of drugs for preterm babies and newborns (2)

- Low coverage of Hepatitis B vaccination for newborns within 24 hours after delivery (2)

- Poor hand washing practices before delivery (2)

- Poor counselling on nutrition for women after caesarean section (2) 


\begin{tabular}{|c|c|c|c|}
\hline & $\begin{array}{l}\text { Commune } \\
\text { level } \\
\text { PeriKIP } \\
\text { group }\end{array}$ & $\begin{array}{l}\text { Hospital } \\
\text { level } \\
\text { PeriKIP } \\
\text { group }\end{array}$ & Total \\
\hline Total number prioritised problems & 416 & 88 & 504 \\
\hline Total number of relevant actions & 1054 & 114 & 1168 \\
\hline Total number of prioritised problems being relevant, $\mathrm{n}(\%)$ & $401(96)$ & $\begin{array}{l}88 \\
(100)\end{array}$ & 489 \\
\hline Average number $(n)$ of problems per unit & 8,7 & 22 & $\begin{array}{l}\text { Not } \\
\text { relevant }\end{array}$ \\
\hline $\begin{array}{l}\text { Relevant problems where the group only presented a plan of } \\
\text { relevant actions (i.e., only made a Plan), n (\%) }\end{array}$ & $85(8)$ & $16(14)$ & $101(9)$ \\
\hline $\begin{array}{l}\text { Relevant problems were the group presented a plan of relevant } \\
\text { actions, undertook the actions, and presented the result (i.e., } \\
\text { undertook Plan-Do and Study), n (\%) }\end{array}$ & $182(17)$ & $14(12)$ & $\begin{array}{l}196 \\
(17)\end{array}$ \\
\hline $\begin{array}{l}\text { Relevant problems were the group presented a plan of relevant } \\
\text { actions, undertook the actions, presented the result, and took } \\
\text { new actions to achieve their goals (i.e., undertook Plan-Do-Study } \\
\text { and Act), n (\%) }\end{array}$ & $787(75)$ & $84(74)$ & $\begin{array}{l}871 \\
(75)\end{array}$ \\
\hline
\end{tabular}

Table 5 Findings from observations of antenatal care 


\section{Domain}

Number

of Units

Number of

Items/Score

Mean Score

Difference

$(95 \% \mathrm{Cl})$

P-

value| $^{1}$

\begin{tabular}{|c|c|c|c|c|}
\hline $\begin{array}{l}\text { Asking questions around the pregnant } \\
\text { woman's health status and reproductive } \\
\text { health history }\end{array}$ & 48 & 36 & $\begin{array}{l}3.82(2.65- \\
5.00)\end{array}$ & $<0.01$ \\
\hline A general examination of the pregnant woman & 48 & 7 & $\begin{array}{l}0.89(0.48- \\
1.29)\end{array}$ & $<0.01$ \\
\hline Performing different tests & 48 & 7 & $\begin{array}{l}0.30(0.09- \\
0.51)\end{array}$ & $<0.01$ \\
\hline $\begin{array}{l}\text { Tetanus vaccination (counselling and } \\
\text { provision of vaccines) }\end{array}$ & 48 & 2 & $\begin{array}{l}0.56(0.28- \\
0.84)\end{array}$ & $<0.01$ \\
\hline Provision of essential drugs & 48 & 5 & $\begin{array}{l}1.75(1.24- \\
2.26)\end{array}$ & $<0.01$ \\
\hline Health education for pregnant women & 48 & 4 & $\begin{array}{l}0.35(0.01- \\
0.70)\end{array}$ & $<0.05$ \\
\hline $\begin{array}{l}\text { Danger signs during pregnancy, birth } \\
\text { preparedness, and feed-back on } \\
\text { examinations }\end{array}$ & 48 & 17 & $\begin{array}{l}4.28(3.08- \\
5.49)\end{array}$ & $<0.01$ \\
\hline Recording patient information & 48 & 3 & $\begin{array}{l}0.00(-0.03- \\
0.03)\end{array}$ & 1.00 \\
\hline
\end{tabular}

${ }^{1}$ Based on t-test

Box

Box 1. PeriKIP group stakeholders at three health system levels

Stakeholder groups at commune level: Each commune has one Commune Health Centre providing primary health care. In each of the 48 communes in the study area, one PeriKIP group was established with the following eight participants: 3 Commune Health Centre staff (head of Community Health Centre, midwife and nurse), 1 village health worker, 1 vice chairperson of the Peoples committee, 1 women union representative from community level, 1 women union representative from village level and 1 population officer.

District and provincial hospital level: In each of the district hospitals in the study area and in the provincial hospital one PeriKIP group was established with the following eight participants: 1 midwife from the antenatal care clinic, 1 midwife from labour ward, 1 head nurse of the paediatric department, 1 head of the obstetric department (physician), 1 head of the paediatric department (physician), 1 head of the general planning department, 1 leader from the hospital director board and 1 representative from Reproductive Health Centre at district or provincial level.

\section{Box 2. Domains covered in the observational checklist}


1. Asking questions on the pregnant woman's health and reproductive health history

2. General examination of the pregnant woman

3. Performing different tests

4. Tetanus vaccination (counselling and provision of vaccines)

5. Provision of essential drugs

6. Health education for pregnant women

7. Recording patient information

8. Danger signs during pregnancy, birth preparedness and feed-back on examinations

\section{Figures}

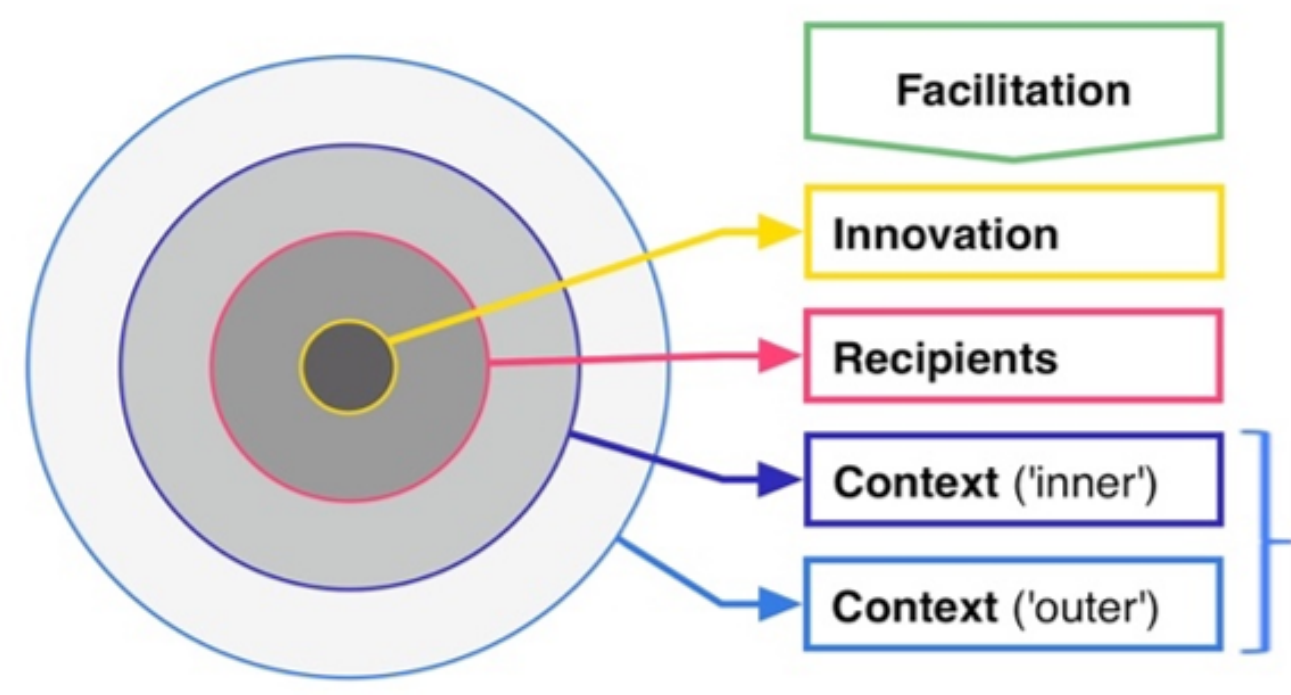

HOW should the implementation of the innovation be facilitated?

WHAT is being implemented?

WHO is being targeted?

WHERE will the innovation be implemented?

Figure 1

The i-PARIHS framework

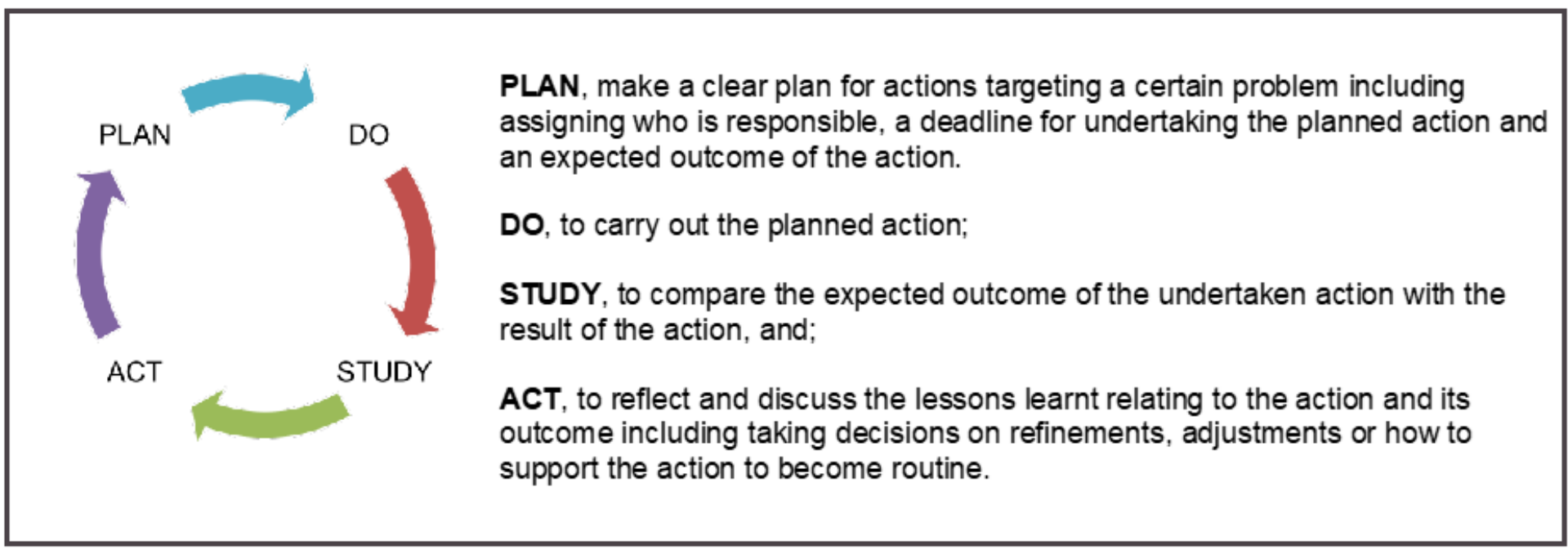


Figure 2

The Plan-Do-Study-Act cycle

\section{Supplementary Files}

This is a list of supplementary files associated with this preprint. Click to download.

- LogicmodelAdditionalfile1formanuscript.pdf

- KnowledgeAssessmentAdditionalfile2formanuscript.pdf

- ANCobservation160304Additionalfile3formanuscript.pdf

- TIDieRChecklistPDF.pdf 